\title{
Grifo: marcas da primeira revista de Mato Grosso do Sul ${ }^{1}$
}

\author{
Mario Luiz FERNANDES ${ }^{2}$ \\ Gustavo ZAMPIERI ${ }^{3}$
}

Resumo:

A revista Grifo foi lançada simultaneamente à implantação do estado de Mato Grosso Sul em janeiro de 1979, constituindo-se, portanto, na primeira revista criada no novo estado. Foi um projeto de jovens jornalistas que retratou a realidade e as expectativas dos sul-mato-grossenses na nova configuração geopolítica. Este artigo relata a breve, mas significativa trajetória da publicação que teve apenas sete edições e um ano de duração. Trata-se de pesquisa que articula a história da revista e a análise de seu conteúdo editorial, com o objetivo de analisar as representações feitas pela revista sobre o primeiro ano do estado. Está estruturada em pesquisa bibliográfica, pesquisa documental e entrevista. A Grifo desenvolveu um jornalismo notadamente interpretativo, que buscou abordar em profundidade as temáticas mais latentes do recém-instalado estado de Mato Grosso do Sul.

Palavras-chave: História da imprensa. Revista Grifo. História da revista. Imprensa de Mato Grosso do Sul.

\section{Grifo: marks of the first magazine of Mato Grosso do Sul}

\begin{abstract}
:
Grifo magazine was launched simultaneously with the implantation of the state of Mato Grosso Sul in January 1979 , constituting, therefore, the first magazine created in the new state. It was a project of young journalists that portrayed the reality and expectations of the people of Mato Grosso do Sul in the new geopolitical configuration. This article reports the brief but significant trajectory of the publication, which had only seven editions and one year in duration. This is a research that articulates the magazine's history and the analysis of its editorial content in order to analyze the representations made by the magazine about the state's first year. It is structured in bibliographic research, documentary research and interview. Grifo developed a notably interpretive journalism that sought to address in depth the most latent themes in the newly installed state of Mato Grosso do Sul.
\end{abstract}

Keywords: History of the press. Grifo magazine. History of the magazine. Mato Grosso do Sul press.

\section{Grifo: marcas de la primera revista de Mato Grosso do Sul}

\section{Resumen:}

La revista Grifo se lanzó simultáneamente con la implantación del estado de Mato Grosso do Sul en enero de 1979, constituyendo, por tanto, la primera revista creada en el nuevo estado. Fue un proyecto de jóvenes periodistas que retrató la realidad y las expectativas del pueblo de Mato Grosso do Sul en la nueva configuración geopolítica. Este artículo da cuenta de la breve pero significativa trayectoria de la publicación, que tuvo solo siete ediciones y un año de duración. Se trata de una investigación que articula la historia de la revista y el análisis de su contenido editorial con el fin de analizar las representaciones que hizo la revista sobre el primer año del estado. Está estructurado en investigación bibliográfica, investigación documental y entrevista. Grifo desarrolló un periodismo notablemente interpretativo que buscaba abordar en profundidad los temas más latentes en el recién instalado estado de Mato Grosso do Sul.

Palabras clave: Historia de la prensa. Revista Grifo. Historia de la revista. Prensa de Mato Grosso do Sul.

\footnotetext{
${ }^{1}$ Este artigo foi apresentado originalmente no GT História da Mídia Impressa, no $3^{\circ}$ Encontro Centro-Oeste de História da Mídia, realizado em 2016 pela Associação Brasileira de Pesquisadores de História da Mídia (Alcar), na Universidade Federal de Mato Grosso do Sul. Foi ampliado e revisado para esta edição da RBHM.

2 Doutor em Comunicação pela Pontifícia Universidade Católica do Rio Grande do Sul. Professor Associado da Universidade Federal de Mato Grosso do Sul. E-mail: mario.fernandes@ufms.br

${ }^{3}$ Graduado em Jornalismo pela Universidade Federal de Mato Grosso do Sul.

E-mail: gustavo.zampieri08@gmail.com
} 


\section{Introdução}

A Grifo era um veículo novo a interpretar a nova realidade de um estado em formação e em transformação política, econômica, cultural e social. Ante ao desafio editorial e empresarial dos jornalistas, este artigo analisa, além da trajetória da revista, qual a sua representação sobre o primeiro ano de Mato Grosso do Sul. Trata-se de uma análise histórica e discursiva tendo por base pesquisa documental, bibliográfica e entrevistas com alguns dos protagonistas da publicação.

Após mais de um século de movimentos visando à separação entre as regiões norte e sul de Mato Grosso, em 11 de outubro de 1977 foi criado o estado de Mato Grosso do Sul, constituído pela porção sul do então Mato Grosso uno. O novo estado do Centro-Oeste brasileiro nascia com 55 municípios, 1,4 milhão de habitantes (BITTAR, 2009) e território de 357,1 mil quilômetros quadrados, o sexto maior do país em extensão. Atualmente, são 79 municípios e população estimada em 2,809 milhões de habitantes (IBGE, 2020). A divisão de Mato Grosso era acalentada desde a Guerra do Paraguai (1864-1870), mas foi no governo de Ernesto Geisel, respaldado pela geopolítica militar e pelo interesse em aumentar a base de sustentação política do regime ditatorial, que ocorreu a emancipação.

Para Bittar (2009, p. 35-36), a grande extensão territorial de Mato Grosso fez com que as regiões norte e sul do estado, além da central, "[...] nunca" chegassem "a constituir exatamente a mesma história", o que gerou “duas formações históricas distintas [...]”. As dificuldades de comunicação e de transportes, as longas distâncias, os diferentes pesos econômicos e de representação política entre as duas regiões foram alguns dos ingredientes propulsores dos diferentes movimentos separatistas (BITTAR, 2009).

A imprensa teve papel ativo ao longo desse processo emancipatório. A primeira manifestação por meio de jornais teria ocorrido já em 26 de outubro de 1894, quando foi lançado em Nioaque, na porção sul de Mato Grosso uno, o semanário A Voz do Sul. Nioaque havia sido elevado a município em 18 de julho de 1890 e no dia 27 do mesmo mês era criado o Partido Republicano em Cuiabá. Foi por força do movimento republicano que Nioaque teve seu primeiro jornal, o segundo do interior de Mato Grosso. O primeiro foi $O$ Iniciador, lançado em Corumbá, em 1877.

Conforme Dalmolin (2016, não paginado), Nioaque era a cidade mais importante politicamente do sul, uma das maiores do estado e "precisava de um instrumento que chegasse a todos os rincões do Apa ao Paraná [rios], levando sua mensagem de positivismo, progresso, 
liberdade, fraternidade e união do sul-mato-grossense". Foi dessa necessidade que nasceu o republicano A Voz do Sul. O periódico foi iniciativa de lideranças republicanas locais e, possivelmente, com auxílio da maçonaria. O vereador e advogado republicano Cláudio Gomes da Silva instalou a primeira tipografia da cidade, foi o impressor e redator do jornal. O material tipográfico foi adquirido do jornal D’A Situação, de Cuiabá, pelo deputado estadual e republicano João Ferreira Mascarenhas.

Dalmolin (2016, não paginado) enfatiza que, "inegavelmente", o primeiro instrumento político que o sul de Mato Grosso criou para defender a região foi A Voz do Sul. Propriedade de João Ferreira de Mascarenhas ${ }^{4}$, o periódico assim se definia em seu artigo de apresentação:

Republicanos de princípios, para nós a República é a chave que coroa a abóboda desse grande edifício de conquistas político-sociais.

Que a República é o único governo que pode fazer a felicidade do Povo Brasileiro: eis as nossas convicções (A VOZ DO SUL, 26 out. 1894, p. 1, apud DALMOLIN, 2016, não paginado).

Pais (2016, não paginado) acrescenta que o jornal foi um "projeto político audacioso que foi, logo, fortemente, combatido pelos líderes mais representativos de Cuiabá [...]”. Foi empastelado em 1896, conforme Mendonça (1963), por um cidadão conhecido por Onça Preta, que jogou o material tipográfico no rio Nioaque.

Quase sessenta anos depois, o movimento sulista reacende em 1954 e tem o apoio do Correio do Estado, criado naquele ano por lideranças políticas ligadas à União Democrática Nacional (UDN) de Campo Grande para defender os ideais do partido. Schwhengber (2008, p. 3) sustenta que o jornal “[...] não escondeu suas intenções e anunciou que era produto e esforço das contribuições espontâneas de políticos e de militares da UDN". O tabloide diário e vespertino tinha oito páginas e tiragem de dois mil exemplares para uma população de aproximadamente 50 mil campo-grandenses. Em sua edição de lançamento, trazia o manifesto pró-divisão, subscrito pelas principais lideranças do sul (SCHWHENGBER, 2008). ${ }^{5}$

Mas é sob o regime militar que a divisão acontece, com base em estudos geopolíticos conduzidos pelo ministro chefe da Casa Civil, Golbery do Couto e Silva. Sua implantação ocorreu em $1^{\circ}$ de janeiro de 1979 com a nomeação do primeiro governador, Harry Amorim

\footnotetext{
${ }^{4}$ João Ferreira de Mascarenhas (coronel Jango Mascarenhas) foi o primeiro intendente de Nioaque, eleito em 1892, aos 28 anos; foi vereador em 1893, presidente do Partido Republicano de Nioaque, deputado estadual em 1894. Em 1899 foi eleito vice-governador do estado (DALMOLIN, 2016).

5 Ainda conforme Schwhengber (2008), o Correio do Estado teve como mentores de sua criação Fernando Correia da Costa (governador), José Manuel Fontanillas Fragelli (primeiro diretor-presidente do periódico, então deputado estadual, e que viria a se tornar deputado federal, governador e senador) e José Inácio da Costa Moraes (principal acionista). Wilson Barbosa Martins, udenista, também integrou esse grupo.
} 
Costa, a instalação da Assembleia Constituinte e de outras instituições (BITTAR, 2009). Nesse novo contexto também se insurgem novos meios de comunicação, agora visando contribuir na consolidação da identidade da nova unidade federativa.

Além das já históricas rádios Difusora AM (1939), Cultura AM (1949) e Imaculada Conceição AM e OT (1960), do jornal Correio do Estado (1954) e da TV Morena (1965), Mato Grosso do Sul nascia contando também com a FM Canarinho (1978) - a atual Mega 94 - a primeira FM de Campo Grande. Já nos primeiros anos, a imprensa da capital recebia o jornal A Crítica (1/08/1980) e a TV Campo Grande (11/10/1980), que atualmente tem a denominação de SBT MS e é afiliada do Sistema Brasileiro de Televisão (SBT) (FERNANDES, 2011). Todos continuam em atividade em 2021, porém, dezenas de jornais surgiram e desapareceram desde a implantação do estado em 1979.

Em janeiro de 1979, portanto, juntamente com a implantação do estado, foi lançado o número zero da revista Grifo. Um projeto liderado pelos jornalistas Marília Leite e Mário Marques Ramires. A revista durou apenas um ano, mas deixou sua marca na história da imprensa do estado. Produziu um jornalismo de análise, de interpretação, pouco praticado no estado e, dessa forma, instigou um novo fazer jornalístico local.

Scalzo (2003) ressalta que, historicamente, enquanto os jornais nascem do engajamento político, a revista surge como um meio de entretenimento, de complementação da educação, de aprofundamento dos assuntos, da segmentação de leitores, do serviço utilitário. Logo, a revista une entretenimento, educação, prestação de serviço e interpretação dos acontecimentos. Possui menos "notícias quentes" e mais informação pessoal (aquela que ajuda o leitor em seu cotidiano, em sua vida prática).

\section{Grifo: seus idealizadores e seus ideais}

Exatos 167 anos após o lançamento da primeira revista no Brasil - As Variedades ou Ensaios de Literatura, criada por Manuel Antônio da Silva Serva, em janeiro de 1812, em Salvador -, um grupo de jovens e idealistas lança a Grifo em janeiro de 1979, em Campo Grande, a capital de Mato Grosso do Sul.

A notícia sobre a criação de Mato Grosso do Sul, em 1977, foi estampada em muitos jornais brasileiros. Foi em um deles, o Jornal da Tarde, fixado em uma banca de revistas no centro de São Paulo, que a jovem campo-grandense Marília Leite, estudante de Jornalismo na Fundação Armando Álvaro Penteado (FAAP), tomou conhecimento da novidade. Nas letras 
em destaque na manchete, ela percebeu que era o momento de retornar à terra natal e desenvolver um projeto que contribuísse na formação do novo estado. A ideia de uma revista surgiu de imediato. O próximo passo foi buscar parcerias. Seu marido, o paulista e também jornalista Mário Marques Ramires, foi o primeiro a aderir. Outros jovens jornalistas paulistas também encamparam a proposta, como o casal Neusa e Jorge João Chacha - que viria a ser reitor da Universidade Federal de Mato Grosso do Sul ${ }^{6}$ de 1996 a 2000 -, Miriam Duailibi e José Márcio Licerre, ${ }^{7}$ entre outros (LEITE, 2016, informação verbal). ${ }^{8}$

Após muitas articulações e cheio de ideias, o grupo rumou para Campo Grande. Com Marília Leite e Mário Ramires à frente do empreendimento, foi constituída a Editora Matogrossense Ltda, instalada em duas salas alugadas no nono andar do edifício localizado à rua 26 de Agosto, $\mathrm{n}^{\circ}$ 384. Meses depois, a editora foi transferida para a rua Dos Barbosas, $\mathrm{n}^{\circ}$ 42 (LEITE, 2016, informação verbal). A equipe era formada por 14 profissionais, entre jornalistas (seis), diagramadores, setores administrativo e financeiro, além de publicitário. Havia também 18 colaboradores que enviavam textos de diferentes pontos do país. Marília assinava como jornalista responsável. A fotocomposição era realizada na Tipografia Jornal do Comércio, os fotolitos em policromia no Estúdio Policolor (São Paulo) e a impressão dos dois mil exemplares na Gráfica Alvorada, em Campo Grande. Capa, contracapa e algumas páginas internas eram coloridas. Contava com representantes comerciais no Rio de Janeiro e em São Paulo (GRIFO, n. zero, jan. 1979).

No editorial da edição número zero, ${ }^{9}$ a Grifo apresenta-se como um “"[...] veículo de ideias. De troca de ideias, palpites e opiniões". Sobretudo, entre aqueles que viviam "a realidade do oeste brasileiro". Sua proposta editorial estendia-se além das questões regionais e se propunha a acompanhar as mudanças que estavam ocorrendo no país. O breve editorial assinala ainda que "a opção por uma revista está ligada a própria origem da proposta, que é grifar, de maneira clara e agradável os aspectos mais significativos do momento [...]”. A revista buscava estimular a troca de opiniões entre seus leitores, colaboradores e entrevistados. Adverte que se trata de um trabalho "essencialmente jornalístico, desvinculado

\footnotetext{
${ }^{6}$ A Universidade Federal de Mato Grosso do Sul foi federalizada em 5/06/1979, um dos últimos atos do primeiro governo de Mato Grosso do Sul, que se encerrou no dia 12 daquele mês. A história da instituição iniciou em 1962, com a criação da Faculdade de Farmácia e Odontologia de Campo Grande. Em 1969 foi criada a Universidade Estadual de Mato Grosso, unindo institutos de ensino de Campo Grande, Corumbá e Três Lagoas (UNIVERSIDADE FEDERAL DE MATO GROSSO DO SUL, s.d.).

${ }^{7}$ Em 1989 foi criado o curso de Jornalismo da UFMS e pouco tempo depois Mário Ramires e Márcio Licerre tornaram-se professores do curso. Ramires faleceu em setembro de 2012.

${ }^{8}$ LEITE, Marília. Entrevista concedida a Mario Luiz Fernandes, Campo Grande, 11 maio 2016.

${ }^{9}$ Apesar de, no editorial, a revista se apresentar como "primeiro número", a capa não traz o número da edição. Trata-se da edição de apresentação. Na edição seguinte, de março, a capa assinala edição número 1.
} 
de quaisquer grupos de interesses políticos ou econômicos particulares" (GRIFO, n. zero, jan. 1979, p. 3).

Marília Leite acrescenta que a opção pelo suporte revista foi também em razão de não haver outra publicação semelhante em Campo Grande e pelo fato desse veículo possibilitar um conteúdo mais elaborado, sem a pressa de um jornal diário ou semanário. A inspiração foi a revista Realidade, editada pelo grupo Abril entre 1966 e 1976, e que se tornou referência de qualidade do jornalismo literário e interpretativo no Brasil.

A capa da edição zero traz como manchete "Está nascendo um novo estado". Estampa um mosaico com fotos em detalhes de duas crianças, uma jovem, um casal de adultos e um idoso, além de uma panorâmica da cidade e de uma lavoura, como ícones das principais riquezas do estado: sua gente e sua terra. Nada de políticos, empresários ou lideranças locais, apenas pessoas das mais simples, o povo. Das 68 páginas, onze e meia eram de anunciantes diversos que apoiam e dão sustentabilidade financeira ao projeto. Em tempos de alta inflação, o preço do exemplar iniciou em 20 cruzeiros e, na última, chegou a 40.

Ao longo da breve história, além de seu conteúdo de vínculo social, a Grifo retratou personalidades que entraram para a história. Marília Leite destaca a entrevista de perfil com o poeta Manoel de Barros, quando ele ainda não tinha a notoriedade nacional dos dias atuais. A entrevista feita por José Octávio Guizzo é entremeada com seis poesias do homem que declara ter se tornado poeta por ter "inaptidão para o diálogo". Na introdução da entrevista, a Grifo acentua sua vertente literária, inspirada em Realidade, e o jornalista descreve Manoel de Barros como "homem íntegro, afável, de sorriso solto, humor afilado". Que "seus cabelos começam a pratear", e os "óculos dependurados no nariz compõem a figura de um intelectual honesto, de posições definidas e sobretudo avançadas” (GUIZZO, 1979, n. 2, p. 50).

Outro personagem destacado é o advogado Wilson Martins (1917-2018), que viria a ser governador do estado em dois mandatos (1983-1986; 1995-1999), além de senador, deputado federal e prefeito de Campo Grande. Iniciou carreira política filiado à UDN em 1945 e após o golpe de 1964 filiou-se ao MDB. Martins fora cassado pelo regime militar em 1969 e ficou dez anos afastado da vida política, atuando apenas como advogado. Sua aparição na Grifo, conforme a revista, foi uma das primeiras na imprensa local após o início do processo de abertura política promovido pelo então presidente João Figueiredo.

Wilson Martins e Manoel da Barros tornaram-se colaboradores da publicação, assim como mais de duas dezenas de jornalistas de diferentes pontos do país como Rio de Janeiro, 
Goiânia, Cuiabá, Curitiba, Uberaba, entre outros.

O entretenimento foi uma das características da revista. As tirinhas da personagem Maria Dadô, criada especialmente por Marlene Mourão, ${ }^{10}$ a Peninha, destilavam humor ácido e crítica social desde a edição zero. Segundo Marlene, foram Marília Leite e Mário Ramires que sugeriram a criação de uma personagem que representasse a cultura regional, pantaneira.

Maria Dadô é a junção de dois nomes comuns: Maria e das Dores. Mulher batalhadora que simbolizava a humildade e a simplicidade, "sempre procurando colocar as coisas em ordem e pondo os filhos "por diante" e no "caminho da retidão", conforme define Marlene Mourão. A personagem era casada com Zétonhi (José Antônio), homem que aparecia sempre de cócoras, fumando ou lendo jornal. Para Marlene, os quadrinhos são um meio de comunicação de extrema importância e através deles a autora conseguiu expor várias críticas sociais.

A autora relata que Dadô teve fãs de várias idades e fez muito sucesso, sendo alvo de comentários e elogios na seção de cartas. "Havia uma mulher conhecida que me ligava e morria de rir... parece coisa de louco, mas é verdade", lembra Marlene. Com o fechamento da Grifo, Dadô “adormeceu” por longos anos, mas retornou em 2007 pelas mãos da jornalista Lívia Gaertner. Virou livro em 2012 e, atualmente, às sextas-feiras, saem novas tirinhas da personagem no Diário Corumbaense.

Segundo Marília Leite, a revista teve boa circulação. Essa era uma das preocupações de seus diretores: ter uma boa carteira de anunciantes e boa vendagem em banca para não depender de mídia do governo e assim manter sua independência editorial. Porém, apesar do sucesso entre os leitores, o número de anúncios foi reduzindo, e isso passou a dificultar a sobrevivência da revista. Marília assinala que houve proposta de apoio de políticos, mas aceitá-la seria perder a independência editorial. Então, os diretores decidiram pelo fechamento e a última edição circulou em dezembro de 1979.

\section{Grifando as pautas do novo estado}

A Grifo publicou sete edições, variando de 68 a 92 páginas, cada uma. Não apresentava editorias fixas, mas no contexto político e histórico no qual se inseria, assuntos como política, economia, meio ambiente, questão indígena, entre outros, foram pautas recorrentes a retratar a realidade e os desafios de um estado em construção. O predomínio era dos gêneros jornalísticos opinativo - notadamente artigos; informativo - nota, notícia,

\footnotetext{
${ }^{10}$ MOURÃO, Marlene. Entrevista concedida a Gustavo Zampieri, via telefone, Campo Grande, 20 maio 2016.
} 
reportagem e entrevista; e interpretativo - enquete, dossiê, perfil e cronologia (MELO; ASSIS, 2013). Boa parte desses formatos era expressa em linguagem literária, própria do jornalismo de revista, para facilitar a compreensão do leitor em relação a temas tão complexos.

A pauta política está presente em todas as edições em reportagens sobre a criação do estado, a anistia dos políticos brasileiros exilados, a eleição da Assembleia Constituinte estadual. Na área econômica, a existência ou não de petróleo em Mato Grosso do Sul, o agronegócio, o garimpo de pedras preciosas; na social, a questão de disputas de terras, o cotidiano de cidades do interior, além das belezas e riquezas naturais do estado, são algumas das pautas frequentes.

A reportagem de capa da edição zero - "Está nascendo um novo estado" - apresenta em 17 páginas o perfil do primeiro governador, Harry Amorim. ${ }^{11}$ Ele fora nomeado pelo presidente Ernesto Geisel. Amorim era gaúcho, engenheiro e diretor geral do Departamento Nacional de Obras e Saneamento (DNOS). Até então, estivera poucas vezes em Campo Grande, apenas para inspecionar obras. A expectativa era de que algum político local fosse o nomeado, o que não ocorreu.

O relato é humanizado e destaca aspectos do carisma do governador, mas enfatiza questões mais agudas, como as polêmicas sobre sua nomeação e as brigas de lideranças políticas locais na disputa pelo poder. A reportagem é seguida da entrevista com Amorim e longa enquete com 32 populares que expressam suas expectativas sobre a divisão do estado e o governador. Há entrevistas com representantes da Igreja, do Exército e da Justiça, que falam sobre o que muda em suas respectivas áreas no novo estado.

Outra questão polêmica. Campo Grande, agora elevada ao status de capital, vivia uma situação singular. Durante a ditadura militar os prefeitos das capitais eram indicados pelos governos estaduais, enquanto nos demais municípios eram eleitos pelo povo, o que era a situação do então prefeito de Campo Grande, Marcelo Miranda Soares ${ }^{12}$. Porém, agora seus sucessores seriam nomeados, fato que Soares era contra, conforme entrevista que concedeu na reportagem da edição zero da Grifo.

\footnotetext{
${ }^{11}$ Harry Amorim governou de 1\%01 a 12/06 de 1979. Foi sucedido pelo então presidente da Assembleia Legislativa, Londres Machado (de 13 a 30/06/1979) e pelo ex-prefeito de Campo Grande, Marcelo Miranda Soares (de 30/06/1979 a 28/10/1980). Soares voltou a ser governador, agora eleito, de 15/03/1987 a 15/03/1992 (ASSEMBLEIA LEGISLATIVA DE MS, s.d.).

${ }^{12}$ Marcelo Miranda Soares foi eleito prefeito de Campo Grande pela Aliança Renovadora Nacional (Arena) em 31/01/1977 e permaneceu no cargo até 29/06/1979, quando assumiu o governo do estado e foi substituído na prefeitura por Albino Coimbra Filho (29/06/1979 a 07/11/1980) e Leon Denizart Conte (07/11/1980 a 19/11/1980). Levy Dias (19/11/1980 a 06/04/1982) foi o primeiro dos quatro prefeitos de Campo Grande nomeados pelo governo do estado (ASSEMBLEIA LEGISLATIVA DE MS, s.d.).
} 
Ainda no campo político, outra questão crucial: a instalação da Assembleia Constituinte do Estado" ${ }^{13}$. Na capa da edição número 1 (março), a manchete: "Uma nova constituição vem aí! O que a gente ganha com isso?”. A reportagem é acompanhada de mais uma extensa enquete com 30 pessoas opinando sobre o que é constituição e o que ela poderia "trazer de bom para o novo estado". Na segunda parte da reportagem, uma mesa redonda com sete deputados constituintes. Eles expuseram suas opiniões, intercalados por perguntas dos repórteres, pontuando as principais contribuições da futura constituição para os mais diversos campos de atividades do estado.

Da política à economia, a exploração das riquezas naturais de Mato Grosso também foi pauta. A reportagem "O eterno fascínio do diamante está na pedra, não na vida do garimpo" aborda a exploração de diamantes no município de Poxoréu e em seu distrito de Alto Coité, a 250 quilômetros de Cuiabá. O texto faz o resgate histórico da exploração de diamantes desde os tempos bíblicos até os atuais, nos países que concentram as maiores jazidas do mundo.

No Brasil, a estimativa de extração de diamantes na década de 70 era de 60 quilos/ano dos quais $70 \%$ eram contrabandeados para outros países. Mato Grosso destacava-se nessa produção e cerca de 3.200 garimpeiros atuavam em Poxoréu. A Grifo denuncia que cerca de dois mil deles trabalhavam em condições "primitivas". Relata a exploração internacional na região por meio da Mineração São José, empresa multinacional com capital norte-americano. Trabalhadores são entrevistados para relatar suas experiências no garimpo.

Em 20 páginas, a reportagem “Agricultura, uma saída para salvar a pátria?” discorre sobre a retomada da agricultura como uma das pontes para o desenvolvimento econômico do Brasil. As adversidades e potencialidades, principalmente do café e da soja, são contextualizadas no cenário econômico brasileiro e expostas as expectativas dos agricultores com a nova legislação para o setor e com o novo ministro Delfim Neto, que apresenta 20 propostas para estimular o setor, além de novos programas para o desenvolvimento da agropecuária. A soja é apontada como "nova esperança" - em razão de suas diversas formas de consumo - que gera grandes lucros em muitos municípios brasileiros. Porém, matéria assinada por Neuza Santana adverte sobre a devastação provocada pela monocultura, os altos custos de produção, a reforma agrária, o problema da Amazônia e alguns conflitos de outros

\footnotetext{
${ }^{13}$ A Assembleia Constituinte de Mato Grosso do Sul foi instalada em 1\%/01/1979 com a posse dos 18 deputados constituintes. Seu presidente era Londres Machado e o relator da constituinte, Ramez Tebet. O governador nomeado, Harry Amorim da Costa, administrou o estado por meio de decretos-lei até a promulgação da Constituição, ocorrida em 13 de junho de 1979 (ASSEMBLEIA LEGISLATIVA DE MS, s.d.).
} 
estados. Por fim, são expostos depoimentos sobre o assunto, desde o prefeito e secretário até fazendeiros e pequenos agricultores.

O meio ambiente foi temática recorrente com reportagens sobre as belezas naturais, a importância de alguns pontos turísticos do estado, além de alertar sobre os riscos de degradação da natureza. Com visual gráfico moderno para a época, a reportagem "Entre as visões e os mistérios da Chapada" mostra o esplendor da Chapada dos Guimarães e como e por quem o local foi descoberto. Faz a descrição detalhada de trilhas pelo seu interior, suas riquezas e as sensações que as pessoas têm durante o percurso.

Na mesma vertente preservacionista, a reportagem "Poucos lucram destruindo o que é de todos" tem como ponto de partida o tema da Campanha da Fraternidade de 1979: o meio ambiente. A revista adverte que apesar de Mato Grosso/Mato Grosso do Sul ainda terem grandes concentrações de florestas, rios e animais, há problemas "esquecidos" ou considerados "pequenos", que, se não forem sanados, produzirão um grande desastre ecológico. Denuncia os riscos gerados por "poucas pessoas": os latifundiários e pessoas de posses.

Música, dança, cultura, cinema, teatro, exposições, festivais e jogos também foram temas constantes. Antes mesmo da criação do atual rótulo de "sertanejo universitário", a revista chamava atenção para o fenômeno de modernização da música sertaneja. A reportagem "Música sertaneja, de sertão mesmo, só saudade", assinada por Pedro Ramires e Dante Filho, revela as mudanças sofridas pela música caipira de raiz em razão da moderna música sertaneja (final dos anos 70) criada para atender o gosto do mercado.

O Bozó ou Pebolim, que contagiava jovens e adolescentes nos finais de 70, não passou despercebido pela Grifo. Das suas origens, como chegou às cidades e orientações sobre como praticá-lo, a revista fez ampla reportagem sobre o jogo.

Outra forma de entretenimento da época era a discotheque ou discoteca. "Dançar, dançar, dançar. Ninguém pode parar?” relata como o fenômeno contagia os jovens campograndenses no comportamento e na moda. Mostra também como músicos "verdadeiros" estavam em dificuldades com a redução do número de shows. Enquete com muitos jovens revela que, para eles, a discoteca era a melhor opção para os finais de semana, seja para dançar, paquerar ou apenas se divertir com os amigos. Para o músico Miguel, tecladista e líder do conjunto Kirtuz, a discoteca atrapalhava o mercado de trabalho da categoria, mas era apenas uma moda passageira. 
"Professores em greve. A Universidade existe" reporta sobre a greve dos professores na então Universidade Estadual do Mato Grosso, a atual UFMS. A matéria conta a história da instituição e como ela evoluiu, contudo, não foi o suficiente. Havia vários problemas de infraestrutura e principalmente a falta de salário dos professores.

Campo Grande, agora como capital, enfrenta novos desafios. "A cidade hoje (sob controle até certo ponto)" aponta algumas deficiências, como no transporte urbano, habitação, saúde, abastecimento, habitação e saneamento básico, sendo este último o pior dos problemas, segundo a revista.

A cobertura sobre temas internacionais e nacionais era feita basicamente com artigos assinados por Alceu Simões Nader, Edmilson Costa e Mário Ramires. "O tirano de Uganda. Exagero?" referencia o genocídio que ocorria em Uganda, atribuído ao seu então presidente Idi Amim Dada; "Figueiredo na Arena", trata da filiação do general João Batista de Oliveira Figueiredo à Arena; "As ditaduras e aberturas da América Latina" expõe o cenário político latino dominado por regimes ditatoriais; "Com qual partido o povo fica?" aborda a abertura politica e o surgimento de vários partidos a partir de 1979. Essas e outras reportagens evidenciam que a revista buscava levar o leitor a reflexões não apenas de questões locais.

O interior do estado teve seu espaço. "Três Lagoas, meu amor” aborda a história daquele município, seu potencial econômico, a localização estratégica para o fluxo de mercadorias entre Mato Grosso do Sul e São Paulo, a importância do rio Paraná e a construção da usina de Jupiá, em 1967. Corumbá foi a capa da edição de setembro. São mostrados diferentes aspectos da cidade, como suas belezas naturais, o pantanal, questões políticas, história, turismo e personalidades locais. Na mesma edição, Paranaíba também teve amplo perfil com sua história e a do trovador e poeta Dico Quirino, 61 anos, além da entrevista com o prefeito do município.

Em um estado com a segunda maior população indígena do país, a Grifo tratou da questão em quase todas as suas edições. "Índio sem terra não é índio" faz um resumo da história dos índios no estado e seus problemas com o governo e latifundiários. Chama atenção para a importância da emancipação dos índios, denuncia que eles estão morrendo e sendo extintos, enquanto o governo dá atenção aos latifundiários. Entrevista D. Thomás Balduino, presidente do Conselho Indigenista Missionário (CIMI) e bispo de Goiás Velho, sobre como é o trabalho do CIMI nas aldeias indígenas e qual a sua importância.

Entrevistas e mesas redondas eram alguns dos recursos jornalísticos utilizados pela 
revista para dar voz e vez às diversas correntes de opiniões que refletissem sobre as perspectivas do novo estado. Governador, prefeitos, ministros, poetas (como Manoel de Barros) ou pessoas comuns eram assíduas em suas páginas. Um exemplo é o "bate-papo" com 12 mães e três repórteres mulheres da Grifo. O foco era discutir o papel e os desafios da mulher na sociedade e na família. Marido, criação dos filhos, o tabu que era a mulher trabalhar para ajudar nas despesas de casa, os obstáculos e preconceitos sofridos pela "mãe solteira" foram alguns dos assuntos debatidos.

Sua última edição traz um formato jornalístico até então inédito na revista: um dossiê. Em 23 páginas, faz um amplo diagnóstico sobre a possibilidade de haver ou não petróleo no estado. A premissa parte da existência da grande reserva de gás natural na Bolívia, que faz fronteira com Mato Grosso do Sul. Situado na mesma área geológica, seria natural que o estado também tivesse essas jazidas. A Petrobras havia feito sondagens, mas interrompeu o processo.

Com linguagem literária, o dossiê inicia com uma longa conversa imaginária entre frequentadores de um bar discutindo o alto preço do litro da gasolina e suas implicações internacionais e problemas gerados no Brasil, como o racionamento do combustível e o consequente aumento do custo de vida. O diálogo simples puxa o fio da meada para a discussão sobre o problema do petróleo no país e a possibilidade da existência de jazidas em Mato Grosso do Sul. Histórico sobre a exploração do petróleo, fotos, mapas, relatórios técnicos de perfurações de poços realizadas pela Petrobrás, gráficos, indicadores e outras informações contextualizam de modo aprofundado o leitor sobre o processo. A revista não conclui se há ou não petróleo no estado, mas fornece dados para que o leitor tire suas conclusões.

A fotografia é outro elemento que reforça o posicionamento editorial da Grifo. Em todas as capas retrata pessoas comuns em cenas cotidianas. Não há políticos, pessoas famosas ou fotos produzidas (posadas). Nas fotos das páginas internas, o número de políticos e de outras lideranças não chega a ser expressivo. O que predomina é o povo, além das belezas naturais, das rotinas das cidades, entre outras características do estado. 


\section{Considerações finais}

A imprensa é um espaço privilegiado para a construção de memórias, de identidades e de representações sociais capazes de gerar e fixar imagens e sentidos acerca dos fatos, pessoas, espaços e datas. A revista Grifo se insere nesse contexto, valendo-se de pelo menos duas das essências do jornalismo: a informação e a interpretação.

Ao estabelecer a associação entre jornalismo investigativo e jornalismo interpretativo ou analítico, Dines (1986) acentua:

O leitor de hoje não quer apenas saber o que acontece à sua volta, mas assegurar-se da sua situação dentro dos acontecimentos. Isto só se consegue com o engrandecimento da informação a tal ponto que ela contenha os seguintes elementos: a dimensão comparada, a remissão ao passado, a interligação com outros fatos, a incorporação do fato a uma tendência e a sua projeção para o futuro (DINES, 1986, p. 90).

Mais que reportar acontecimentos, a Grifo, com suas densas e consistentes reportagens, entrevistas, enquetes, artigos, entre outros formatos textuais, empreendeu esforço no sentido de seguir os fundamentos jornalísticos elencados por Dines e inserir o cidadão no processo de mudança, o qual estava em curso no recém-criado Mato Grosso do Sul. Pode-se dizer que, por meio de sua cobertura jornalística, o leitor depreendeu esse processo de mudança.

De curta duração - sete edições em um ano - a Grifo deixou sua marca na história da imprensa de Mato Grosso do Sul, não apenas por ser a primeira revista do novo estado ou pela profundidade e consistência com as quais o apresentou a seus leitores, mas também pela forma como retratou os valores e as expectativas de sua gente. A revista estampou lideranças políticas em suas páginas, até para que a população tomasse conhecimento de seus atos, de suas propostas para o estado, mas foi o povo o seu personagem principal. Enquetes, entrevistas, fotos, opiniões de populares prevaleceram. As frequentes enquetes somam 150 populares entrevistados e praticamente todos eles acompanhados por suas fotos. Era a janela para que o povo pudesse ver a si próprio.

A revista trouxe para o estado jornalistas com formação acadêmica, o que era raro na época, já que o primeiro curso de Jornalismo de Mato Grosso do Sul, o da Universidade Federal, foi criado só em 1989, por reivindicação do sindicato da categoria. A maioria das empresas jornalísticas era atrelada a grupos políticos locais e o jornalismo praticado tinha um forte vínculo partidário. A Grifo inovou não apenas em termos do conteúdo e independência 
editorial, mas também no uso da linguagem literária e na profundidade com que tratava os temas, aspectos poucos praticados pelo jornalismo local de então. Após o fechamento da revista, seus jornalistas passaram a atuar em outros veículos de Campo Grande.

Conforme Beltrão (1980, p.12), ao traçar um paralelo e complementariedade entre duas das essências do jornalismo - informar e interpretar - " "[...] a atualidade tem de ser interpretada, porquanto informação e orientação são funções básicas sociais do periodismo [...]". Para o autor, "a interpretação jornalística consiste no ato de submeter os dados recolhidos no universo das ocorrências atuais e ideias atuantes a uma seleção crítica, a fim de proporcionar ao público os que são realmente significativos". Ao se fazer a leitura das edições da Grifo, depreende-se que esse foi seu compromisso: registrar e interpretar o que ocorria de mais significativo no fato histórico em curso, extrair o permanente do fato corrente, ou seja, o que era mais significativo na estruturação do novo estado.

Mais recentemente, ao conceituar a interpretação como um gênero jornalístico, Melo e Assis (2013) estratificam o jornalismo interpretativo em quatro formatos: dossiê, perfil, enquete e cronologia. Cada um desses formatos foi explorado pela revista para explicar e dar sentido ao leitor sobre os fatos que se sucediam. De questões comportamentais, como as mudanças no modo de namorar, às expectativas sobre o novo estado, a população pôde se manifestar sobre variados assuntos.

Outro elemento que realça sua relevância é o contexto socio-histórico no qual estava inserida: a implantação do estado de Mato Grosso do Sul. Um território e um povo que já possuíam seu lastro histórico, econômico, cultural e social, mas que, a partir de 1979, passaram a reordená-los e a ressignificá-los a partir de uma nova perspectiva identitária delineada pela nova configuração geopolítica autônoma. Aquela necessidade de reafirmação de ser um cidadão do estado de Mato Grosso do Sul, como a população costuma corrigir nos eventos públicos quando o orador ou artista convidado esquece de acrescentar o "do Sul".

Uma das missões da Grifo foi reforçar os elementos da identidade cultural de Mato Grosso do Sul por meio de suas representações acerca da cultura, das tradições, das riquezas naturais, do cotidiano, dos costumes. A outra missão foi levantar reflexões sobre as questões políticas, econômicas e os desafios de um estado nascente. 
Referências

ASSEMBLEIA LEGISLATIVA DE MATO GROSSO DO SUL. História. [S.d.]. Disponível em: https://al.ms.gov.br/Paginas/1/historia. Acesso em: 27 fev. 2021.

BELTRÃO, Luiz. Jornalismo interpretativo. Porto Alegre: Sulina, 1980.

BITTAR, Marisa. Mato Grosso do Sul, a construção de um estado. Campo Grande: Editora UFMS, 2009. v. 1: Regionalismo e divisionismo no sul de Mato Grosso.

DALMOLIN, José Vicente. O jornal A Voz do Sul 1894. In: Nioaque e as histórias no contexto do Mato Grosso do Sul do século XIX ao XXI. Capítulo XV. 16 abr. 2016. Disponível em: http://nioaquehistorias.blogspot.com.br/2016/04/o-jornal-voz-do-sul1894.html. Acesso em: 23 mar. 2017.

DINES, Alberto. O papel do jornal. São Paulo: Summus, 1986.

GRIFO. Editorial, Campo Grande, n. zero, p. 3, jan. 1979.

FERNANDES, Mario Luiz. Panorama do rádio em Campo Grande. In: PRATA, Nair (org.). Panorama do rádio no Brasil. Florianópolis: Insular, 2011, p. 131-148.

GRIFO. Campo Grande: Editora Matogrossense, 1979. Número zero a 6.

GUIZZO, José Octávio. Manoel de Barros: sobreviver pela palavra. Grifo, Campo Grande, n. 2, p. 50, maio, 1979.

IBGE - INSTITUTO BRASILEIRO DE GEOGRAFIA E ESTATÍSTICA. 2020. Disponível em: https://www.ibge.gov.br/cidades-e-estados/ms.html. Acesso em: 27 fev. 2021.

MELO, José Marques de; ASSIS, Francisco de (org.). Gêneros jornalísticos no Brasil. São Paulo: Metodista, 2013.

MENDONÇA, Rubens de. História do jornalismo em Mato Grosso. Cuiabá: 1963.

PAIS, Luiz Carlos. A Voz do Sul de Nioaque (1894). Recanto das Letras. 16 ago. 2016. Disponível em: http://www.recantodasletras.com.br/artigos/5730627. Acesso em: 23 abr. 2017.

SCALZO, Marília. Jornalismo de revista. São Paulo: Contexto, 2003.

SCWHENGBER, Isabela de Fátima. Aspectos históricos do jornal Correio do Estado. In: ENCONTRO NACIONAL DA REDE ALFREDO DE CARVALHO, 6., 2008, Niterói. Anais [...]. Porto Alegre: UFRGS, 2008. p. 1-13. Disponível em: http://www.ufrgs.br/alcar/encontros-nacionais-1/encontros-nacionais/6o-encontro-20081/Aspectos\%20historicos\%20do\%20jornal\%20Correio\%20do\%20Estado.pdf. Acesso em: 27 fev. 2021.

UNIVERSIDADE FEDERAL DE MATO GROSSO DO SUL. Histórico. [S.d]. Disponível em: https://www.ufms.br/universidade/historico/ Acesso em: 02 mar. 2021. 


\section{Entrevistas}

LEITE, Marília. Entrevista concedida a Mario Luiz Fernandes, Campo Grande, 11 maio 2016. MOURÃO, Marlene. Entrevista concedida a Gustavo Zampieri, via telefone, Campo Grande, 20 maio 2016.

Submetido em 14.07.2019

Aprovado em 31.08.2020 